\title{
Water resources and water management for environmental integration in the Euro-Mediterranean region
}

\author{
Maurizio Barbieri $^{1}$ \\ Published online: 28 May 2021 \\ (C) Saudi Society for Geosciences 2021
}

The Euro-Mediterranean region is currently covering political, economic, and social challenges and an ever-growing environmental degradation that has made environmental and resource protection an increasingly important issue. These aspects have also rekindled the debate on revitalizing the EuroMediterranean integration process using solid cooperative projects in various sectors, especially environmental awareness, assessment, and improvement. This integration process is mainly intended to lessen the development gap between the northern and southern borders of the Mediterranean and to create new and closer political, economic, social, cultural, and, most importantly, scientific links between the two based on common concerns. Sustainable development is a global purpose that aims to reply to the needs of current generations without negotiating the capacities of future generations to meet their own needs. They also highlight the requirement to change unsustainable production and consumption models, protect and manage natural resources sustainably for economic and social development, safeguard health, and combine the objective of sustainable development more efficiently into globalization. Despite the progress made, there is a hidden but increasing awareness throughout the Euro-Mediterranean that current growth trends are unsustainable. Euro-Mediterranean people are becoming more aware that it is impossible to keep using resources, build up coastal areas, and develop industries, especially tourism, without an adequate integrated planning framework, reducing North-South disparities and the necessary policy reforms. The challenge for Euro-Mediterranean countries is

This article is part of the Topical Collection on Water resources and water management for environmental integration in the EuroMediterranean region

Maurizio Barbieri

maurizio.barbieri@uniroma1.it

1 Department of Earth Sciences (DST), Sapienza University of Rome, Piazzale Aldo Moro 5, 00185 Roma, Italy to use the environment as an opportunity to make coordinated and joint progress in the fields of human and economic development, environmental protection, and cultural advancement. It is crucial to ending the environmental degradation that is already giving rise to very high economic and social costs. The region also needs to redirect its development to meet the economic and social needs considered in the South and East, without increasing environmental degradation. The environment in the Euro-Mediterranean societies forms the basis for the development of the region. It is crucial to ending the environmental degradation that is already giving rise to very high economic and social costs. The region also requires redirecting its development to meet the economic and social needs considered in the South and East, without rising environmental degradation. The structure, status, and processes of the environment system, which can only be acquired through scientific research efforts, are critical aspects of sustainable growth. Methodologies based on hydrology, hydrogeology, and hydrogeochemistry in water resource assessment, development, and management activities are already scientifically established. They are an integral part of many water resource investigations and environmental studies. This special issue of the AJGS takes concurrently the state of the art of research in water resources and water management in the EuroMediterranean region based on the best contributions that were presented at the 1st Euro-Mediterranean Conference for Environmental Integration (EMCEI 2017), held in Sousse, Tunisia, 22-25 November 2017. The driving force that delayed this Special Issue was the need to point the hydrological and water resource management societies during up-to-date research and best practices. The papers gathered in this Special Issue offer a specific overview of current research on emerging environmental issues and challenges and related applications to various problems in the Euro-Mediterranean concerning approaching problems and opportunities scientifically. A peerreview process selected original research papers to rapid, accessible, and wide dissemination of results. 